\title{
Intravenous Thrombolysis in a Stroke Patient Receiving Rivaroxaban
}

\author{
Felix Fluri Florian Heinen Christoph Kleinschnitz \\ Department of Neurology, University Clinic Würzburg, Würzburg, Germany
}

\section{Introduction}

Rivaroxaban, a novel direct factor Xa inhibitor with consistent anticoagulant properties, was found to be safer and equally effective as warfarin in the prevention of embolic stroke in patients with nonvalvular atrial fibrillation [1,2]. Effective anticoagulation predisposes to bleeding and represents a contraindication for intravenous thrombolysis (IVT) with recombinant tissue plasminogen activator (rtPA), the only approved therapy for acute ischemic stroke [3]. However, the clinical outcome and the risk of symptomatic intracranial hemorrhage (ICH) after IVT in stroke patients treated with rivaroxaban have so far been unknown.

\section{Case Report}

An 83-year-old man with a history of nonvalvular atrial fibrillation, heart failure (NYHA class III), biventricular pacing, hypercholesterolemia, arterial hypertension and two previous strokes 4 months and 4 years before admission presented with acute right hemiparesis and dysarthria that lasted for $2 \mathrm{~h}$. The patient was treated with rivaroxaban at a reduced dose of $15 \mathrm{mg}$ once daily. The last intake of rivaroxaban was $21 \mathrm{~h}$ before symptom onset.

On admission, blood pressure was 114/76 mm Hg and the NIHSS score equaled 9. Blood tests showed an increased partial thromboplastin time (41.9 s; normal 23-36), a normal thrombin time (18.9 s; normal 14-21) and a slightly elevated international normalized ratio (INR: 1.41; normal 0.85-1.18). Rivaroxaban plasma concentration was below the detection limit, and anti-factor Xa activity (COATEST ${ }^{\circledR}$; Chromogenix, Lexington, Mass., USA) was absent. Platelet count was normal, whereas renal function was impaired (creatinine 132 $\mu \mathrm{mol} / \mathrm{l}$, normal <103; creatinine clearance according to the Cockcroft-Gault formula $28.2 \mathrm{ml} /$ min). Cranial CT and CT-angiography revealed no early signs of cerebral ischemia or ICH, and the large brain vessels were patent. Since anti-factor Xa activity was absent and the INR was 
$<1.7$ [4], the patient received IVT with $\mathrm{rtPA}$ at $0.9 \mathrm{mg} / \mathrm{kg}$ (total dose $50 \mathrm{mg}$ ) $210 \mathrm{~min}$ after stroke onset. Shortly afterwards, the neurological status rapidly improved. On a follow-up blood examination, partial thromboplastin time (52.5 s) and INR (1.33) continued to be slightly elevated, while renal function was still impaired (creatinine clearance $27.8 \mathrm{ml} / \mathrm{min}$ ). ICH could be ruled out by a follow-up cranial CT. Ultrasound examination of the cerebral vasculature was normal, as was echocardiography. Twenty-four hours after thrombolysis, creatinine clearance had increased above $30.0 \mathrm{ml} / \mathrm{min}$, and treatment with dabigatran 110 mg twice daily was initiated. The NIHSS score at discharge was 1.

\section{Discussion}

To the best of our knowledge, this is the first report of a patient with acute ischemic stroke undergoing IVT despite rivaroxaban pretreatment. One could speculate that the favorable clinical outcome and the absence of bleeding complications in this case were related to the reduced dose of rivaroxaban as well as the relatively long interval between the last drug intake and IVT. Longer dosing intervals were also associated with a good functional outcome in stroke patients taking another direct oral anticoagulant (DOAC), dabigatran, before IVT [5-7], whereas a fatal ICH occurred in another patient who underwent thrombolysis only $3 \mathrm{~h}$ after dabigatran intake [8].

The conditions under which acute stroke patients taking DOAC should receive IVT remain unclear in the absence of sensitive coagulation tests [9]. Many of the current guideline committees have not updated their recommendations since the introduction of DOAC. These drugs are not addressed even in the most recent European guidelines [10], whereas other updated guidelines [4] recommend discontinuing the rtPA administration until the results of accurate hematologic tests are known. However, IVT in rivaroxaban-treated patients may be considered if the plasma concentration of rivaroxaban is $<100 \mathrm{ng} / \mathrm{l}$ or if anti-factor Xa activity is normal [11]. Importantly, the present case underlines that testing for established coagulation parameters in patients receiving DOAC is unreliable [11] and emphasizes the urgent need for sensitive bed-site tests during emergencies.

\section{Disclosure Statement}

C. Kleinschnitz received a speaker honorarium, compensation for travel expenses and financial support for scientific projects from Bayer Healthcare. Moreover, he received a speaker honorarium and compensation for travel expenses from Boehringer Ingelheim and Pfizer. F. Fluri and F. Heinen have nothing to disclose.

\section{References}

1 Patel MR, Mahaffey KW, Garg J, Pan G, Singer DE, Hacke W, et al: Rivaroxaban versus warfarin in nonvalvular atrial fibrillation. N Engl J Med 2011;365:883-891.

-2 Hankey GJ, Patel MR, Stevens SR, Becker RC, Breithardt G, Carolei A, et al: Rivaroxaban compared with warfarin in patients with atrial fibrillation and previous stroke or transient ischaemic attack: a subgroup analysis of ROCKET AF. Lancet Neurol 2012;315-322.

-3 Wardlaw JM, Murray V, Berge E, del Zoppo G, Sandercock P, Lindley RL, et al: Recombinant tissue plasminogen activator for acute ischaemic stroke: an updated systematic review and meta-analysis. Lancet 2012;379: 2364-2372. 
4 Jauch EC, Saver JL, Adams HP, Bruno A, Connors JJ, Demaerschalk BM, et al: Guidelines for the early management of patients with acute ischemic stroke: a guideline for healthcare professionals from the American Heart Association/American Stroke Association. Stroke 2013;44:870-947.

$\checkmark 5$ De Smedt A, De Raedt S, Nieboer K, De Keyser J, Brouns R: Intravenous thrombolysis with recombinant tissue plasminogen activator in a stroke patient treated with dabigatran. Cerebrovasc Dis 2010;30:533-534.

-6 Matute MC, Guillán M, García-Caldentey J, Buisan J, Aparicio M, Masjuan J, et al: Thrombolysis treatment for acute ischaemic stroke in a patient on treatment with dabigatran. Thromb Haemost 2011;106:178-179.

7 Marrone LCP, Marrone ACH: Thrombolysis in an ischemic stroke patient on dabigatran anticoagulation: a case report. Cerebrovasc Dis 2012;34:246-247.

-8 Casado Naranjo I, Portilla-Cuenca JC, Jiménez Caballero PE, Calle Escobar ML, Romero Sevilla RM: Fatal intracerebral hemorrhage associated with administration of recombinant tissue plasminogen activator in a stroke patient on treatment with dabigatran. Cerebrovasc Dis 2011;32:614-615.

-9 Samama MM, Guinet C: Laboratory assessment of new anticoagulants. Clin Chem Lab Med 2011;49:761-772.

10 European Stroke Organisation: ESO Guidelines for Management of Ischaemic Stroke Update 2009. http:// www.eso-stroke.org/recommendations.php?cid=9\&sid=1.

11 Steiner T, Böhm M, Dichgans M, Diener H-C, Ell C, Endres M, et al: Recommendations for the emergency management of complications associated with the new direct oral anticoagulants (DOACs), apixaban, dabigatran and rivaroxaban. Clin Res Cardiol 2013;102:399-412. 